\title{
“LER E ESCREVER”: APRECIAÇÃO E ANÁLISE LITERÁRIA.
}

Rosana da Silva Santos Jurazeky, Ana Maria Martins da Costa Santos

Universidade Estadual Paulista/ Faculdade de Ciências e Tecnologia - Presidente Prudente. E-mail: jurazekyrosana@yahoo.com.br

\section{RESUMO}

Ciranda do saber: linguagens literárias e educacionais constitui-se em um grupo de pesquisa e desenvolveu nos anos de 2011-12, uma pesquisa documental de análise do programa Ler e Escrever. Objetivou-se analisar o conteúdo do material no que se refere à formação de professores, investigar a fundamentação teórica e as propostas de atividades de leitura no que se refere à apreciação e análise literária, com vistas a discutir as contribuições para o trabalho do professor em sala de aula e, consequentemente, para a formação do aluno leitor.

Palavras-chave: Ler e escrever; Leitura; Formação de Professores; Apreciação; Análise Literária.

\section{INTRODUÇÃO}

Ciranda do saber: linguagens literárias e educacionais constitui-se em um grupo de pesquisa de caráter multidisciplinar ${ }^{1}$, organizando-se por meio de reuniões presenciais e virtuais visando discutir, refletir e pesquisar sobre temas como ensino da leitura e da literatura. Tendo em vista a ampla implementação do programa Ler e Escrever na Rede Estadual, em diversas redes municipais do Estado de São Paulo, o qual possui um caráter diferenciador, particularmente, em relação a seu material didático e de formação de professores, o grupo desenvolveu, nos anos de 2011-12, uma pesquisa documental de análise desses materiais.

O Programa foi implementado a partir de 2008, na Rede Estadual de Ensino de São Paulo. Por esta razão optamos pela pesquisa de caráter documental, uma vez que caracteriza-se por focalizar minúcias do material, possibilitando o aprofundamento da análise.

\section{OBJETIVO}

Analisar o conteúdo do material no que se refere à formação de professores, investigar a fundamentação teórica e as propostas de atividades de leitura no que se refere, particularmente, à apreciação e análise literária, com vistas a discutir as contribuições para o trabalho do professor em sala de aula e, consequentemente, para a formação do aluno leitor.

\footnotetext{
${ }^{1}$ O grupo de pesquisa é coordenado pela Profa Dra Ana Maria Martins da Costa Santos 


\section{METODOLOGIA}

Para esse objetivo se cumprir, a metodologia adotada foi a análise documental, tendo como fonte primária os materiais didáticos oferecidos aos professores, que participam do Programa Ler e Escrever. A definição por esta metodologia se justifica pela necessidade de pesquisas teóricas capazes de avaliar a qualidade dos conceitos que adentram as salas de aula das escolas públicas e se transformam em documentos básicos de sustentação das ações pedagógicas. Assim, a análise documental focaliza as minúcias dos materiais, a fim de compreender o que é exposto e por que. A divulgação de resultados de pesquisas documentais acrescenta considerações teórico-reflexivas ao universo da pesquisa em educação, ampliando, desse modo, o conhecimento conceitual que é imprescindível para a realização eficiente das práticas de ensino voltadas à aprendizagem dos alunos.

Neste artigo será apresentado o resultado de um dos focos da pesquisa: apreciação e análise literária. Portanto, não serão analisadas as atuações dos formadores do Ler e Escrever ou o impacto do Programa nas escolas, pois o foco de estudo da pesquisa como um todo foi a análise dos materiais oferecidos aos professores como guias de estudo e de orientações metodológicas.

Segundo Gil (2000, pp.97-98), há quatro etapas no processo da análise documental: "definição dos objetivos; elaboração do plano de trabalho; coleta de dados; análise e interpretação". A definição dos objetivos é, na maioria dos casos, o objetivo proposto, a descrição das características de determinado grupo, fato, ou fenômeno. No caso desta pesquisa, foi a definição de análise dos materiais do Programa Ler e Escrever relacionada à concepção de formação continuada de professores para as séries iniciais.

A elaboração do plano de trabalho implica determinar com precisão os dados a serem coligidos e a maneira como tais dados serão organizados e analisados. Nesta pesquisa, refere-se à leitura dos materiais didáticos do Programa Ler e Escrever, à pesquisa sobre formação continuada de professores, à leitura de referenciais teóricos sobre leitura e escrita, à escrita da análise do material didático analisado.

A coleta de dados é feita naturalmente em arquivos ou outros dispositivos que contenham os dados a serem analisados. Neste caso, a coleta de dados aconteceu com base nos materiais didáticos do Programa Ler e Escrever.

A etapa de análise e interpretação acontece por meio do aporte teórico construído, analisando e interpretando o documento. De posse dos dados a serem analisados e com o referencial teórico construído, acontece a análise, pautada nos objetivos traçados, e a 
interpretação. Por último, sintetiza-se o resultado da análise e interpretação, elaborando a conclusão do trabalho.

Assim a presente pesquisa teve quatro focos de análise que serão apresentados a seguir:

1. O programa Ler e Escrever e a formação continuada de professores: avanços e desafios: por Cláudia Regina Bachi e Gislene Aparecida da Silva Barbosa

2. Alfabetização nos anos iniciais do Ensino Fundamental: considerações sobre a proposta do Ler e Escrever para o 10 ano: por Simone Conceição Pereira Deák e Sandra Aparecida Tavares Barbosa do Nascimento

3. Estratégias de leitura: ler para aprender e aprender para ler: por: Vania Kelen Belão Vagula e Rita de Cássia Nespoli Damasceno.

4. Apreciação e analise literária: uma prática pedagógica necessária desde os primeiros anos do ensino fundamental, ciclo I: por Elisabete Mota de Oliveira e Rosana da Silva Santos Jurazeky

Para os fins deste artigo, ater-me-ei na apresentação e discussão do último foco que foi meu objeto de estudo ${ }^{2}$.

\section{DISCUSSÃO}

O último enfoque dado à pesquisa foi relativo a algumas concepções teóricas sobre a apreciação e análise literária estabelecendo um paralelo com os materiais do Programa Ler e Escrever (do 1ㅇ. ao 5ㅇ. ano do Ensino Fundamental) verificando as possibilidades das propostas subjacentes contribuírem para a formação do leitor literário.

As questões norteadoras foram: Qual é o significado da palavra apreciar? Qual é o valor atribuído à prática de apreciação literária no Programa Ler e Escrever, para os 1ㅇ, 2o e 3o anos do Ensino Fundamental Ciclo I $?^{3}$ E qual a importância das práticas pedagógicas que fazem acontecer à apreciação literária no contexto escolar?

Segundo a definição de Aurélio em seu minidicionário da língua portuguesa o termo apreciar é" Dar apreço, merecimento, estimar, prezar. julgar, avaliar". (2001, p.54). Coelho (2003, p. 43) ao abordar a prática da apreciação a coloca como uma forma critica de discussão sobre uma

\footnotetext{
${ }^{2}$ Ao leitor, sugerimos a leitura do livro “Programa de Formação de Professores 'Ler e Escrever': avanços e desafio do trabalho docente no processo de alfabetização e letramento", organizado pela Profa Dra Ana Maria Martins da Costa Santos, publicado pela Editora CRV, em 2013, no qual consta os resultados completos desta investigação.

3 - Os Guias de Planejamentos e Orientações Didáticas para o professor do Programa Ler e Escrever se refere às séries, 1a․ e 2a․, mas empregaremos neste texto o termo ano devido ao sistema de ensino atual, pois com a promulgação da lei 11.274 regulamentou-se o Ensino Fundamental de 9 anos.
} 
determinada obra e comparação com leituras realizadas anteriormente, no que se refere ao conhecimento oculto de cada leitor. Explorando assim, o título, personagens, ilustração e informações em releituras.

Apreciar um texto literário vai além da leitura superficial, requer uma análise completa da obra, em profundidade; isto significa considerar o autor, época em que foi escrita, público alvo, intenções do autor, estilo, aspectos estéticos e ideológicos. Para tanto, o leitor deve ter parâmetros para esta análise, pois não é possível apreciar sem ter um aporte teórico e um repertório de leituras que sustente esta análise.

\section{RESULTADO}

Ao analisarmos os materiais do Ler e Escrever verificamos que há uma valorização da literatura infantil nos primeiros anos de escolarização, já em contrapartida nos materiais destinados aos 4ㅇ e 50 anos a continuidade da construção de comportamento leitor e o estudo da literatura com sentido humanizador dá espaço aos estudos lingüísticos, em particular, ao ensino da gramática.

Notou-se, então, que não há uma sequência lógica na abordagem dos conceitos sobre como deve ser realizada a apreciação literária, podendo confundir o professor no que concerne à fundamentação teórica e orientações didáticas.

Entendemos que para que o professor realize práticas de apreciação literária é fundamental ter conhecimentos teóricos que possam sustentar a análise de textos literários.

Ao analisar o Guia considerou-se positiva a proposta da "Leitura de duas versões"4, o exercício de análise comparativa e a produção da terceira versão pelos alunos. Porém, a função estética é pouco desenvolvida apenas uma atividade, com ênfase na linguagem e nas escolhas que cada escritor faz em determinado momento. Em diversos momentos do Guia encontramos atividades de apreciação e análise literária, para exemplificar selecionamos apenas uma para este artigo, afim de esclarecer ao leitor a ênfase dado ao aspecto gramatical do texto.

\footnotetext{
4 Ver "Atividade 21: Leitura pelo professor - analise de duas versões" em:SÃO PAULO (ESTADO) Secretaria da Educação. Ler e Escrever. Guia de Planejamento e Orientações Didáticas - Professor Alfabetizador - 1ạ. série. São Paulo: FDE, 2010,v. 2, p. $122-123$. 


\section{ATIVIDADE 21: LEITURA PELO PROFESSOR}

\section{Comparação e análise de trechos de duas versōes da mesma história}

\section{Objetivos}

Aproximar-se da linguagem usual em contos de fadas.

- Comparar formas diferentes de expressar o mesmo conteúdo em duas versões de contos de fadas.

Ampliar os recursos discursivos.

\section{Planejamento}

Quando realizar? Depois da Atividade 20.

Como organizar os alunos? A atividade é coletiva, eles podem ficar em suas carteiras.

Que materiais são necessários? Os trechos das histórias selecionados que você irá ler.

Duração: cerca de 40 minutos.

\section{Encaminhamento}

Selecione previamente alguns trechos de diferentes versões de boa qualidade que utilizem linguagem diferente. Em geral, o início e alguns trechos em que a ação da história é decisiva permitem boas comparações. Veja, por exemplo, este trecho que selecionamos.

\section{Chapeuzinho Vermelho - duas versōes do início da história \\ VERSÃO 1}

\section{Início}

Houve, uma vez, uma graciosa menina; quem a via ficava logo gostando dela, assim como ela gostava de todos; particularmente, a amava a avozinha, que não sabia o que dar e o que fazer pela netinha. Certa vez, presenteou-a com um chapeuzinho de veludo vermelho e, porque Ihe ficava muito bem, a menina não mais quis usar outro e acabou ficando com o apelido de Chapeuzinho Vermelho.

\section{Diálogo}

- Oh, vovó, que orelhas tão grandes tens!

- São para melhor te ouvir. 
- Oh, vovó, que olhos tão grandes tens!

- São para melhor te ver

- Oh, vovó, que mãos enormes tens!

- São para melhor te agarrar.

- Mas vovó, que boca medonha tens!

- É para melhor te devorar.

Contos e lendas dos Irmãos Grimm, volume 5. Tradução de Íside M. Bonini. São Paulo: Edigraf.

\section{VERSÃO 2}

\section{Início}

Era uma vez uma menininha linda de quem todo mundo gostava, principalmente a avó dela, que não sabia o que podia inventar para agradá-la. Certa vez, deu a ela um chapeuzinho de veludo vermelho que ficou tão bem que ela queria botar todo dia. Por isso, todo mundo acabou chamando a menina de Chapeuzinho Vermelho.

\section{Diálogo}

- Vovó, que orelhas tão grandes você tem!

- São para te ouvir melhor...

- Vovó, que olhos tão grandes você tem!

- São para te ver melhor...

- Vovó, que mãos tão grandes você tem!

- São para te pegar melhor...

- Vovó, que boca tão grande e terrível você tem!

- É para te comer melhor...

Releia o início e os demais trechos selecionados das duas histórias.

Após ler cada trecho, converse com os alunos a respeito das diferenças entre as duas formas de contar a história: como cada autor inicia a história? Como cada um apresenta as personagens?

É importante deixar claro que as escolhas realizadas pelo autor podem tornar o texto mais bonito e mais agradável de ler. Você pode desenvolver essa atividade no mesmo dia em que for propor a produção oral com destino escrito. A partir desta atividade, você pode criar uma situação de reflexão sobre o sistema de escrita para os alunos não-alfabéticos: proponha a escrita ou a leitura de uma lista de palavras utilizadas em ambas as versões para se referir às personagens ou a um dos cenários da história. 
As atividades de leitura realizadas pelo aluno exigem um conhecimento sobre o sistema de escrita e gramatical e não sobre linguagem literária e estética como indicados nos objetivos, e que, a meu ver, não foram atingidos na proposta de atividades.

Com a análise aprofundada da obra, isto implica considerar os aspectos gramaticais, semânticos e pragmáticos (Chiappini, 1998) o professor poderá desenvolver atividades que auxiliem o aluno na compreensão do texto, seja pela fruição, seja para a reescrita. Neste sentido, compartilhamos as ideias de Colomer (2002, p. 94):

O estudo dos conteúdos literários programados, os trabalhos de observação e análise das obras, comentário detalhado de uma obra lida de forma coletiva, a relação da leitura com projetos de escrita criativa, etc., devem ser atividades diferenciadas da situação real da leitura e integrada nas linhas de programação de auxílio escolar que se propõe a aumentar a capacidade de compreensão dos alunos com intenção de que possam transferir os conhecimentos adquiridos a todas as obras que venham a ler automaticamente.

\section{CONSIDERAÇÕES FINAIS}

Até o momento percebemos que este programa e, em particular, seus materiais representam historicamente um avanço significativo: 1. por tratar da formação de professores, tanto em relação à fundamentação teórica, como nas orientações didáticas e sistematização do trabalho docente para as séries iniciais; 2. por apresentar uma grande diversidade de textos, em especial, as coletâneas dos alunos, pois propicia inúmeras possibilidades de leituras de diferentes gêneros textuais; 3.por destacar algumas propostas para o trabalho de análise e apreciação literária.

Porém, é preciso atentar-se para o fazer pedagógico. Os objetivos propostos nos Guias são relevantes para a formação do aluno leitor, mas cabe ao professor contextualizar e ampliar as atividades a fim de que seja feita a apreciação e análise literária, mais profundamente, isto significa não enfatizar apenas o aspecto gramatical do texto. Assim o aluno poderá ler nas linhas e entrelinhas do texto literário e poderá construir seu próprio repertório literário.

\section{REFERÊNCIAS}

CHIAPPINI, L. Aprender e ensinar com textos didáticos e paradidáticos. v. II, São Paulo: Cortez, 1998.

COELHO, N.N. O conto de fadas: símbolos, mitos e arquétipos. São Paulo: Difusão Cultural do Livro, 2003. 
COLOMER, Tereza. Ensinar a ler, ensinar a compreender. Porto Alegre: Artmed, 2002.

FERREIRA, Buarque de Holanda. Mini Aurélio Século XXI Escolar: O minidicionário da língua portuguesa. 4. ed. rev. ampliada. Rio de Janeiro: Nova Fronteira, 2001

GIL, Antonio Carlos. Técnicas de Pesquisa em Economia e elaboração de monografias. São Paulo: Atlas, 2000.

SANTOS, A. M. M. C. Programa de Formação de Professores Ler e Escrever: avanços e desafios do trabalho docente no processo de alfabetização e letramento. Curitiba, PR: CRV, 2013.

SÃO PAULO (ESTADO), Secretaria da Educação. Ler e escrever: Guia de Planejamento e Orientações Didáticas; professor - 2o ano (1a série). 4. ed. São Paulo: FDE, 2010a. 2v.

. Ler e escrever: Guia de Planejamento e Orientações Didáticas; professor - 3o ano (2aㅡ série). 4. ed. São Paulo: FDE, 2010b. 2v.

. Ler e escrever: Guia de Planejamento e Orientações Didáticas; professor - 4으 ano (3a série). 3. ed. São Paulo: FDE, 2010 c.

. Ler e escrever: Guia de Planejamento e Orientações Didáticas; professor - 5o ano (4aㅡ série). 3. ed. São Paulo: FDE, 2010d.

. Ler e escrever: Guia de estudo para Horário de Trabalho Coletivo: subsídios para o coordenador pedagógico. São Paulo: 2006.

. Ler e escrever: guia de planejamento e orientações didáticas; professor alfabetizador - 10 ano/Secretaria da Educação, Fundação para o Desenvolvimento da Educação; concepção e elaboração, Claudia Rosenberg Arantagy... (e outros) - São Paulo: FDE, 2011. 